\title{
The association between frailty and incidence of dementia in Beijing: findings from 10/66 dementia research group population-based cohort study
}

Minghui Li ${ }^{1}$, Yueqin Huang ${ }^{1{ }^{*} \dagger}$, Zhaorui Liu ${ }^{1{ }^{*}}$, Rui Shen ${ }^{1}$, Hongguang Chen ${ }^{1}$, Chao Ma ${ }^{1}$, Tingting Zhang ${ }^{1}$, Shuran $\mathrm{Li}^{1}$ and Martin Prince ${ }^{2}$

\begin{abstract}
Background: The relationship between frailty and dementia is unclear and there are very few population-based studies regarding this issue in China. The purpose of this study is to estimate the association between frailty and incident dementia in China, and to explore different effects of frailty established by three definitions of frailty on dementia incidence.
\end{abstract}

Methods: A five-year prospective cohort study was carried out in 2022 participants aged 65 years and over in urban and rural sites in Beijing, China. The participants were interviewed by trained community primary health care workers from 2004 to 2009. Frailty was defined using modified Fried frailty phenotype, physical frailty definition, and multidimensional frailty definition. Dementia was diagnosed using the 10/66 dementia criterion for calculating cumulative incidence. Both competing risk regression models and Cox proportional hazards models were applied to examine the associations between frailty at baseline and five-year cumulative incidence of dementia.

Results: At the end of follow-up the five-year cumulative incidence rates of dementia with frailty and without frailty defined by the modified Fried frailty were $21.0 \%$ and $9.6 \%$, those defined by the physical frailty were $19.9 \%$ and $9.0 \%$, and those defined by the multidimensional frailty were $22.8 \%$ and $8.9 \%$, respectively. Compared with non-frail participants, frail people had a higher risk of incident dementia using multidimensional frailty definition after adjusting covariates based on competing risk regression model ( $H R=1.47,95 \% \mathrm{Cl} 1.01 \sim 2.17)$ and Cox proportional hazards model ( $H R=1.56,95 \% \mathrm{Cl} 1.07 \sim 2.26)$. The association between frailty and incident dementia was statistically significant in participants in the upper three quartiles of age (aged 68 years and over) using the multidimensional frailty definition based on the competing risk regression model $(H R=1.61,95 \% \mathrm{Cl} 1.06 \sim 2.43)$ and Cox proportional hazard model $(H R=1.76,95 \% \mathrm{Cl} 1.19 \sim 2.61)$.

(Continued on next page)

\footnotetext{
* Correspondence: huangyq@bjmu.edu.cn; zhaoruiliu@bjmu.edu.cn

${ }^{\dagger}$ Yueqin Huang and Zhaorui Liu contributed equally to this work.

'Peking University Sixth Hospital, Peking University Institute of Mental Health,

National Health Committee Key Laboratory of Mental Health (Peking

University), National Clinical Research Center for Mental Disorders (Peking

University Sixth Hospital), Beijing, China

Full list of author information is available at the end of the article
}

(c) The Author(s). 2020 Open Access This article is licensed under a Creative Commons Attribution 4.0 International License, which permits use, sharing, adaptation, distribution and reproduction in any medium or format, as long as you give appropriate credit to the original author(s) and the source, provide a link to the Creative Commons licence, and indicate if changes were made. The images or other third party material in this article are included in the article's Creative Commons licence, unless indicated otherwise in a credit line to the material. If material is not included in the article's Creative Commons licence and your intended use is not permitted by statutory regulation or exceeds the permitted use, you will need to obtain permission directly from the copyright holder. To view a copy of this licence, visit http://creativecommons.org/licenses/by/4.0/ The Creative Commons Public Domain Dedication waiver (http://creativecommons.org/publicdomain/zero/1.0/) applies to the data made available in this article, unless otherwise stated in a credit line to the data. 
(Continued from previous page)

Conclusions: Multidimensional frailty may play an inherent role in incident dementia, especially in the people aged over 68, which is significant for distinguishing high risk people and determining secondary prevention strategies for dementia patients.

Keywords: Ageing, Frailty, Dementia, Follow-up, Cumulative incidence

\section{Background}

The number of people with dementia worldwide is rising within the ageing population, which is a severe issue in all countries. The World Health Organization (WHO) reports that there are almost 50 million people currently living with dementia, and nearly 10 million new cases each year [1], with the highest growth area being in China and some other developing nations [2]. According to the China Mental Health Survey, the prevalence of dementia for the population aged 65 and over is $5.6 \%$ diagnosed by the Diagnostic and Statistical Manual of Mental Disorders (DSM)-IV [3-5]. Moreover, the prevalence is higher if using the 10/66 diagnostic package [6], which is more sensitive for detecting the early stages of dementia.

Because of the limited availability of therapeutic medications for dementia, it is particularly important to identify its risk factors, which can help policy makers distinguish and intervene in high-risk cases. Therefore, considerable attention to risk factors for dementia has been sustained over the last two decades. Age, smoking, hypertension, high cholesterol, and apolipoprotein E are considered likely risk factors for dementia [7]. In addition, there is a consensus that the risk factors of incident dementia occurrence likely cluster with lifestyles, chronic diseases, and physical impairment [8-11]. Moreover, in a meta-analysis on dementia, a relationship was found between exposure to increased factor load and subsequent poorer cognitive function or dementia [12].

Some researchers have suggested integrating risk factors into definition of frailty, which is a comprehensive indicator for evaluating its effects on dementia incidence [13]. Frailty is an age-related syndrome with the main features of impaired multisystem physiological reserves and decreased resistance to substantial stressors [14].

It was estimated that frailty increases the likelihood of future cognitive decline and that cognitive impairment elevates the risk of frailty. However, the mechanism of the potential association between frailty and incident dementia is unclear. It has been shown that physical frailty increases the risk of diabetes mellitus and cardiovascular disease $[15,16]$. Moreover, a clinical-pathologic study found physical frailty to be associated with dementia pathology [17-19], and alterations in hippocampal synaptic function, neuronal membrane properties, and axonal trajectories, which might lead to dementia have been reported for people with frailty [20-22].
Preliminary studies on frailty in China have focused on the association between frailty and death. Dupre reported the relationship between frailty, type of death and suffering death, using the frailty index comprising 39 deficits [23]. The most frequently used frailty assessment methods in China are the Fried phenotype and the frailty index, which are similar to those in other countries. For community-dwelling people aged 65 or over in China, the prevalence of frailty is 5.9\%$17.4 \%$ [24], close to that in developed countries. Nonetheless, very few studies on the relationship between frailty and dementia have been carried out in China. In addition, the prevalence of frailty varied in different studies due to the assessment method employed, and previous studies have shown that the variables selected for assessment methods differwith regard to study aim.

\section{Methods \\ Objective}

The objectives of this study were to estimate the potential association between frailty and incident dementia in China and to explore different effects of frailty established by three definitions of frailty on dementia incidence.

\section{Design and participants}

This study is one part of the 10/66 dementia research group population-based studies, which were carried out in people aged 65 years and over living in 11 catchment areas (China, Cuba, Dominican Republic, India, Mexico, Peru, Puerto Rico, and Venezuela). The present study only included data for China. The participants included were from the baseline survey conducted by trained psychiatrists from January 2004 to April 2005, and all residents aged 65 years and over living in the catchment areas of Xicheng and Daxing were enrolled. Moreover, full follow-up was performed four to five years after the baseline. For deceased participants, the international standard verbal autopsy questionnaire was used to obtain information on death and probable causes or causes of death [25]. Comprehensive details of the study population have been published elsewhere [26].

\section{Measurements Dementia}

The method used for evaluating dementia was the 10/66 dementia diagnosis adjusted education, which was developed by the 10/66 dementia research group; it has been widely 
used in previous studies. The information for establishing diagnoses included the Community Screening Instrument for Dementia (CSI-D), the Geriatric Mental State (GMS), and a structured neurological examination [27, 28]. The CSID was used to collect information on cognitive and functional decline. The GMS was applied to identify organic brain syndrome (probable dementia), depression, anxiety and psychosis. The structured neurological examination assessed whether the participants had lateralizing signs, Parkinsonism, ataxia, apraxia and primitive reflexes. More details about the package have been published elsewhere [29].

\section{Frailty}

In this study, frailty was defined using three types of definitions. The first definition was the modified Fried frailty phenotype, which included four variables: exhaustion, weight loss, slow walking speed, and low energy expenditure. In the 10/66 cohort study, handgrip strength was omitted. Participants were identified as frail if they exhibited two or more of the four variables [30].

Exhaustion was assessed by Q48.1 in the GMS questionnaire. Participants who self-reported feeling worn out or exhausted were considered potentially frail. Weight loss status was evaluated by the question "have you lost $10 \mathrm{lbs}$ (4.5 kilograms) in weight during the past three months?" Slow walking speed was defined by a walking timing test (walk $5 \mathrm{~m}$ at usual speed, turn, and return to the starting point), applying the cut-off point of $16 \mathrm{~s}$ or longer to complete the task to indicate frailty.

The second definition was generated using the Rockwood frailty index construction [31]. Based on the modified Fried frailty phenotype, nine physical impairment items were added to describe frailty constituting physical frailty. The physical impairment items included: finger movement disorder, decreased muscular tension, abnormal tendon reflex, eyesight problems, hearing difficulty or deafness, dysdiadochokinesis, waist-hip ratio ( $\geq 0.85$ in female or $\geq 0.90$ in male regarded as frail), sleeping disorders, and slow action. The participant's frailty index was equal to the number of unhealthy items divided by the total number of items. Frailty was defined as having a physical frailty index (PFI) greater than or equal to 0.25 [32].

The third definition was the multidimensional frailty index (MFI), which added the mental status and social relations of the elderly into the PFI. Items added to the MFI included impairment of general cognitive ability, delayed recall problems, lack of concentration, lack of interest, delayed recall, depressive emotions, loneliness, and insufficient social support.

\section{Other associated assessments}

Other potential risk factors were selected from prior studies, including sociodemographic factors, physical impairments, behaviours and lifestyles.
Sociodemographic factors were collected through interviews, including age, gender, marital status (unmarried, married/co-habiting, widowed/divorced/separated), and education level (none, minimal/completed primary, completed secondary/metric, completed tertiary/college/ further education).

The participants or their proxies reported a history of the following conditions: arthritis/rheumatism, persistent cough, breathlessness/difficulty breathing/asthma, hypertension, cardiopathy/angina, gastrointestinal problems, paralysis/weakness/loss of one leg or arm, skin disorders, fainting or blackouts, and diabetes mellitus [33]. Those participants with three or more physical impairments were defined as having physical multimorbidity. Physical multimorbidity reflected the most common physical impairments that interfere with older people's daily activities.

In the study, alcohol use status (non-drinking, temperance, drinking), smoking status (no smoking, smoking cessation, smoking), and walking distance per week (less than $3 \mathrm{~km}$, more than or equal to $3 \mathrm{~km}$ ) were collected at the same time.

\section{Statistical analysis}

SAS version 9.4 was used for all analyses. Participants who did not have dementia at baseline constituted the cohort. First, the participants' baseline characteristics for each catchment area, including age, gender, education level, marital status, smoking status, and alcohol use status, were collected. Moreover, differences in variables between rural (Daxing) and urban (Xicheng) participants' baselines were compared by percentages and Pearson's chi-square test and the difference in age between the two settings was compared by means and the $t$-test.

For each frailty definition, five-year cumulative incidence rates were calculated and competing risk regression model and Cox proportional hazards model were used for analyses. Competing risk regression models were employed according to the methods of Fine and Gary, taking into account death as the competing risk event of incident dementia. Cox proportional hazards regression models were used to examine the relationship between frailty and mortality in the sample population while controlling for selected covariates. After the unadjusted model (model 1) was determined, further adjustments for age, gender, and education level (model 2) were included. Model 3 included all components of model 1 and model 2, as well as physical multimorbidity, walking distance per week, smoking status and alcohol use. The hazard ratios (HRs) with 95\% confidence intervals (CIs) of incident dementia by frailty are reported.

Regarding Doraiswamy and Bieber's research about dementia assessment scales [34], separate analyses were dichotomized into two groups, the lowest quartile and upper three quartiles of age at baseline. The cut-off 
point was 68 years old. To explore whether age modifies the association between frailty and incident dementia, an interaction term between frailty and age at baseline was derived, controlling for gender, education level, physical multimorbidity and alcohol use.

\section{Results}

\section{Sample characteristics}

The sample characteristics of the analyses are displayed in Table 1. A total of 2087 participants were assessed at baseline; 65 participants who had dementia at baseline were excluded. The mean follow-up period was 4.92 years, with a standard deviation (SD) of 0.99 years. Among the 2022 participants at baseline, 386 died during the follow-up period, with a mortality of $19.1 \%$. The quartiles of age were 68,72 and 76 among all participants. Demographic ageing was more prevalent in the urban site than that in the rural site $(t=5.499, p<$ 0.001 ). The means of age in the rural and urban sites were 72.05 and 73.47 years, respectively (Table 1 ). There were 609 females (56.6\%) in the urban site and 521 (55.1\%) in the rural site. There was no significant difference by gender between the urban and rural sites. Education levels in the urban site were higher than those in the rural site, with "Minimal/completed primary" being the majority $(N=423 ; 39.3 \%)$ among the urban participants. Regarding marital status, 780 (72.5\%) participants in the urban site and $562(59.4 \%)$ in the rural site were married. The prevalence rates of alcohol use in the rural and urban sites were $16.3 \%$ and $3.4 \%$, respectively. The prevalence rate of smoking in the rural site was $30.4 \%$, which was higher than that in the urban site (17.0\%).

\section{Association between frailty and incident dementia}

Table 2 displays the number and percentage of participants deemed frail at baseline and the five-year cumulative incidence of dementia at the end of follow-up. The five-year cumulative incidence of dementia in the participants exhibiting baseline frailty was twice as high as that in the participants deemed not to be frail at baseline. There were 105 modified Fried frail participants at baseline, and $21.0 \%$ of them developed dementia by the end of follow-up. However, only $9.6 \%$ of non-modified Fried frail participants developed dementia. There were 206 physically frail participants and 197 multidimensionally frail participants at baseline. The five-year cumulative incidences of dementia were $19.9 \%$ and $22.8 \%$, respectively.

Table 3 reports the HRs based on competing risk regression models and Cox proportional hazards models. Of the modified Fried frailty phenotype unadjusted models, the HRs generated from the competing risk model and Cox proportional hazards model were 1.71 (95\% CI: $1.09 \sim 2.68)$ and 1.78 (95\% CI: 1.14 2.79) respectively. When adjusting for age, gender and education level, no significant differences in the association between frailty and incident dementia were observed in either model. Of the physical frailty unadjusted models, the HRs based on the competing risk model and the Cox proportional hazards model were 1.78 (95\% CI: 1.25 2.54) and 1.78 (95\% CI: 1.25 2.53), respectively. Of the multidimensional frailty models, when adjusting for age, gender, education level, physical multimorbidity, walking distance per week, smoking status, and alcohol use, the HRs based on the competing risk model and Cox proportional hazards model were 1.47 (95\% CI: 1.01 2.17) and 1.56 (95\% CI, 1.07 2.26), respectively.

The HRs for the competing risk models and the Cox proportional hazards models of three definitions of frailty in two age groups, adjusted gender, education level, physical multimorbidity, walking distance per week, smoking status and alcohol use are provided in Table 4; the boundary was 68 years old as the lowest quartile age [34]. For participants in the upper three quartiles of age, the HRs for multidimensional frailty based on the competing risk model and Cox proportional hazards model were 1.61 (95\% CI: 1.06 2.43) and 1.76 (95\% CI: 1.19 2.61), respectively.

\section{Discussion}

The study is one part of the series of studies on dementia by the 10/66 International Research Group. To date, very few studies have explored the relationship between frailty and dementia. Based on three different definitions of frailty, we explored the probable influence of frailty on the incidence of dementia in elderly people in a Beijing sample. The results indicated that the participants with multidimensional frailty had a higher risk than did non-frail participants and that the size of the effect varied across different age groups. This finding is consistent with previous studies showing that frailty is a risk factor for dementia [35]. The uniqueness of this study is the fact that the competing risk of death was considered when exploring the influence of frailty on incident dementia in China [36], which can result in accurate HRs, despite a limitation to using those experiences directly because of the difference between China and other Western countries. Although the results of the three definitions differ slightly, frailty can generally increase the hazard of incident dementia.

The modified Fried frailty phenotype, which was used in previous frailty studies by 10/66 collaboration group, includes four physical variables, and this definition has been confirmed as a good predictor for dependence and mortality in older adults [30]. Regardless, the results did not prove the association between the modified Fried frailty phenotype and dementia after adjusting for age, gender and education level. In other words, the modified Fried frailty phenotype could not accurately predict the 
Table 1 Sample Characteristics at Baseline

\begin{tabular}{|c|c|c|c|c|c|c|c|c|}
\hline \multirow[t]{2}{*}{$\begin{array}{l}\text { Demographic } \\
\text { Variables }\end{array}$} & \multicolumn{2}{|c|}{$\begin{array}{l}\text { Total } \\
N=2022\end{array}$} & \multicolumn{2}{|c|}{$\begin{array}{l}\text { Urban } \\
N=977\end{array}$} & \multicolumn{2}{|c|}{$\begin{array}{l}\text { Rural } \\
N=948\end{array}$} & \multirow[t]{2}{*}{$t / x^{2}$} & \multirow[t]{2}{*}{$P$} \\
\hline & $\mathrm{N}$ & $\%$ & $\mathrm{~N}$ & $\%$ & $\mathrm{~N}$ & $\%$ & & \\
\hline Gender & & & & & & & 0.5 & 0.49 \\
\hline Female & 1130 & 55.9 & 609 & 56.6 & 521 & 55.1 & & \\
\hline Male & 892 & 44.1 & 467 & 43.4 & 425 & 44.9 & & \\
\hline Age & & & & & & & 34.7 & $<.001$ \\
\hline $65-69$ & 686 & 33.9 & 309 & 28.7 & 377 & 39.9 & & \\
\hline $70-74$ & 635 & 31.4 & 350 & 32.5 & 285 & 30.1 & & \\
\hline $75-79$ & 419 & 20.7 & 236 & 21.9 & 183 & 19.3 & & \\
\hline $80-84$ & 182 & 9.0 & 118 & 11.0 & 64 & 6.8 & & \\
\hline $85+$ & 100 & 5.0 & 63 & 5.9 & 37 & 3.9 & & \\
\hline Mean & 72.80 & & 73.47 & & 72.05 & & $5.499^{*}$ & $<.001$ \\
\hline 25th percentile & 68 & & 69 & & 68 & & & \\
\hline 50th percentile & 72 & & 73 & & 71 & & & \\
\hline 75th percentile & 76 & & 77 & & 75 & & & \\
\hline Education level & & & & & & & 473.6 & $<0.001$ \\
\hline None & 748 & 37.0 & 207 & 19.2 & 541 & 57.2 & & \\
\hline Minimal/completed primary & 781 & 38.6 & 423 & 39.3 & 358 & 37.8 & & \\
\hline Completed secondary/metric & 358 & 17.7 & 316 & 29.4 & 42 & 4.4 & & \\
\hline Completed tertiary/college/further education & 135 & 6.7 & 130 & 12.1 & 5 & 0.5 & & \\
\hline Marital status & & & & & & & 49.0 & $<.001$ \\
\hline Unmarried & 25 & 1.2 & 3 & 0.3 & 22 & 2.3 & & \\
\hline Married/co-habiting & 1342 & 66.4 & 780 & 72.5 & 562 & 59.4 & & \\
\hline Widowed/divorced/separated & 655 & 32.4 & 293 & 27.2 & 362 & 38.3 & & \\
\hline Alcohol use status & & & & & & & 106.8 & $<.001$ \\
\hline No drinking & 1803 & 89.2 & 1031 & 95.8 & 772 & 81.6 & & \\
\hline Temperance & 29 & 1.4 & 9 & 0.8 & 20 & 2.1 & & \\
\hline Drinking & 190 & 9.4 & 36 & 3.4 & 154 & 16.3 & & \\
\hline Smoking status & & & & & & & 63.4 & $<.001$ \\
\hline No smoking & 1449 & 71.7 & 817 & 75.9 & 632 & 66.8 & & \\
\hline Smoking cessation & 102 & 5.0 & 76 & 7.1 & 26 & 2.8 & & \\
\hline Smoking & 471 & 23.3 & 183 & 17.0 & 288 & 30.4 & & \\
\hline
\end{tabular}

$N$ Number of participants

* The difference of age between the two sites was compared by means and t-test

risk of incident dementia in this Chinese sample. To further evaluate the association between physical frailty and incident dementia, nine additional physical variables, including finger movement disorder, decreased muscular tension, abnormal tendon reflex, eyesight problems, hearing difficulty or deafness, dysdiadochokinesis, waisthip ratio, sleeping disorders, and slow action, were added to the modified Fried frailty phenotype forming the PFI, but the result was similar to that of the modified Fried frailty phenotype. The association between PFI and incident dementia was only found in the unadjusted model. Previous population-based studies have reported that physical frailty might be associated with vascular dementia, which accounts for $15 \%$ 20\% of all-cause dementia [37]. As only all-cause dementia was considered in this study, the association between it and physical frailty was not as expected. It is assumed that physical frailty plays different roles in predicting the incidence of different types of dementia. To explore this question more deeply, two age-group analyses were conducted to assess the relationship between frailty and incident dementia.

The mental status and social relations of elderly individuals were added, including impairment of general cognitive ability, delayed recall problems, lack of 
Table 2 Frailty of Prevalence at Baseline and Incidence of Dementia at the End of Follow-up

\begin{tabular}{|c|c|c|c|c|c|}
\hline \multirow[t]{2}{*}{ Model } & \multicolumn{2}{|c|}{ Frailty prevalence at baseline } & \multirow{2}{*}{$\begin{array}{l}\text { 5-year cumulative incidence } \\
\text { of dementia }(\%, 95 \% \mathrm{Cl})\end{array}$} & \multirow[t]{2}{*}{$x^{2}$} & \multirow[t]{2}{*}{$P$} \\
\hline & $\mathrm{N}$ & Prevalence (\%) & & & \\
\hline Modified Fried Frailty & & & & 14.2 & $<.001$ \\
\hline No frailty & 1917 & 94.8 & $9.6(8.2,10.9)$ & & \\
\hline Frailty & 105 & 5.2 & $21.0(13.2,28.7)$ & & \\
\hline Physical Frailty & & & & 24.0 & $<.001$ \\
\hline No frailty & 1816 & 89.8 & $9.0(7.7,10.4)$ & & \\
\hline Frailty & 206 & 10.2 & $19.9(14.2,25.4)$ & & \\
\hline Multidimensional Frailty & & & & 38.7 & $<.001$ \\
\hline No frailty & 1825 & 90.3 & $8.9(7.5,10.1)$ & & \\
\hline Frailty & 197 & 9.7 & $22.8(17.0,28.7)$ & & \\
\hline
\end{tabular}

$N$ Number of participants; $\mathrm{Cl}$ Confidence interval

concentration, lack of interest, delayed recall, depressive emotions, loneliness, and insufficient social support, to the definition of multidimensional frailty. The results showed that multidimensional frailty is an independent predictor for incident dementia and associated with a $47 \%$ increased hazard in the competing risk model after adjusting for age, gender, education level, physical multimorbidity, walking distance per week, alcohol use and smoking status. Most previous studies on frailty have only focused on the physical dimension [16, 17, 38], though there is some evidence showing a relationship between mental status and social relations and incident dementia. In a Japanese dementia study, Shimada interviewed 4570 community-dwelling elderly persons and found that inclusion of a cognitive dimension in the frailty assessment improved the predictive accuracy [39].
This finding suggests that the identification of high-risk populations of dementia should not be limited to one dimension. A better identification should include multidimensional risk factors for identifying high-risk populations and providing advanced intervention. The report of the Lancet International Commission recommended that dementia prevention include more childhood education, exercise, and management of hearing loss and depression [40]. In addition, Rogers derived a frailty index comprising 47 health factors and found that frailty should be considered alongside cognitive function when assessing risk factors of dementia [41]. Furthermore, it has been shown conclusively that cognitive impairment is a potential component of the secondary prevention of dementia [42]. There are several possible explanations for this result. First, frailty is a condition

Table 3 Competing Risk Model and Cox Proportional Hazards Model of Frailty and Incident Dementia by three Frailty definitions

\begin{tabular}{|c|c|c|c|c|c|c|}
\hline \multirow[t]{2}{*}{ Model $^{*}$} & \multicolumn{2}{|c|}{ Modified Fried Frailty Phenotype } & \multicolumn{2}{|l|}{ Physical Frailty } & \multicolumn{2}{|c|}{ Multidimensional Frailty } \\
\hline & $\begin{array}{l}\text { Competing risk } \\
\text { modelHR }(95 \% \mathrm{Cl})\end{array}$ & $\begin{array}{l}\text { Cox proportional } \\
\text { hazards model } \\
H R(95 \% \mathrm{Cl})\end{array}$ & $\begin{array}{l}\text { Competing risk } \\
\text { model HR }(95 \% \mathrm{Cl})\end{array}$ & $\begin{array}{l}\text { Cox proportional hazards } \\
\text { modelHR }(95 \% \mathrm{Cl})\end{array}$ & $\begin{array}{l}\text { Competing risk } \\
\text { model } H R(95 \% \mathrm{Cl})\end{array}$ & $\begin{array}{l}\text { Cox proportional hazards } \\
\text { modelHR }(95 \% \mathrm{Cl})\end{array}$ \\
\hline \multicolumn{7}{|l|}{ Model 1} \\
\hline $\begin{array}{l}\text { No } \\
\text { Frailty }\end{array}$ & 1.00 & 1.00 & 1.00 & 1.00 & 1.00 & 1.00 \\
\hline Frailty & $1.71(1.09,2.68)$ & $1.78(1.14,2.79)$ & $1.78(1.25,2.54)$ & $1.78(1.25,2.53)$ & $2.14(1.53,3.00)$ & $2.15(1.53,3.02)$ \\
\hline \multicolumn{7}{|l|}{ Model 2} \\
\hline $\begin{array}{l}\text { No } \\
\text { Frailty }\end{array}$ & 1.00 & 1.00 & 1.00 & 1.00 & 1.00 & 1.00 \\
\hline Frailty & $1.25(0.78,2.01)$ & $1.33(0.84,2.09)$ & $1.37(0.93,2.01)$ & $1.32(0.92,1.89)$ & $1.65(1.16,2.34)$ & $1.66(1.17,2.33)$ \\
\hline \multicolumn{7}{|l|}{ Model 3} \\
\hline $\begin{array}{l}\text { No } \\
\text { Frailty }\end{array}$ & 1.00 & 1.00 & 1.00 & 1.00 & 1.00 & 1.00 \\
\hline Frailty & $1.14(0.69,1.87)$ & $1.14(0.70,1.84)$ & $1.16(0.78,1.73)$ & $1.24(0.83,1.85)$ & $1.47(1.01,2.17)$ & $1.56(1.07,2.26)$ \\
\hline
\end{tabular}


Table 4 Competing Risk Models and Cox Proportional Hazard Models of Frailty and Incident Dementia in Two Age Groups

\begin{tabular}{|c|c|c|c|c|}
\hline \multirow{2}{*}{$\begin{array}{l}\text { Frailty } \\
\text { definition }\end{array}$} & \multicolumn{2}{|c|}{ Lower quartile of age $(N=538)$} & \multicolumn{2}{|c|}{ Upper three quartiles of age $(N=1484)$} \\
\hline & $\begin{array}{l}\text { Competing risk model } \\
\text { HR }(95 \% \mathrm{Cl})\end{array}$ & $\begin{array}{l}\text { Cox proportional hazards model } \\
\text { HR }(95 \% \mathrm{Cl})\end{array}$ & $\begin{array}{l}\text { Competing risk model } \\
\text { HR }(95 \% \mathrm{Cl})\end{array}$ & $\begin{array}{l}\text { Cox proportional hazards mode } \\
\text { HR }(95 \% \mathrm{Cl})\end{array}$ \\
\hline \multicolumn{5}{|c|}{ Modified Fried Frailty Phenotype } \\
\hline No frailty & 1.00 & 1.00 & 1.00 & 1.00 \\
\hline Frailty & $0.89(0.23,3.50)$ & $0.96(0.16,5.61)$ & $1.25(0.75,2.08)$ & $1.28(0.77,2.15)$ \\
\hline \multicolumn{5}{|c|}{ Physical Frailty } \\
\hline No frailty & 1.00 & 1.00 & 1.00 & 1.00 \\
\hline Frailty & $1.94(0.481,7.80)$ & $2.13(0.48,9.37)$ & $1.28(0.83,1.96)$ & $1.38(0.92,2.08)$ \\
\hline \multicolumn{5}{|c|}{ Multidimensional Frailty } \\
\hline No frailty & 1.00 & 1.00 & 1.00 & 1.00 \\
\hline Frailty & $1.520 .47,4.86)$ & $1.643(0.46,5.84)$ & $1.61(1.06,2.43)$ & $1.76(1.19,2.61)$ \\
\hline
\end{tabular}

$N$ Number of participants; HR Hazard Ratio; Cl Confidence interval

*Risk of incident dementia is adjusted age, gender, education level, physical multimorbidity, walking distance per week, smoking status alcohol use

that is characterized by a reduction in the homeostatic reserves of the individual, which entails an increased vulnerability to endogenous and exogenous stressors [43]. Hence, frail people face more challenges in adapting to significant threats that may occur in that individual's life. In other words, frail people's resilience may decline, which will increase the likelihood of dementia. Second, frailty and dementia might have a similar aetiological pathway because both are related to cognitive decline [41]. The aetiology of frailty is multidimensional, including nutrition, physical activity, coping, social support and other potential causes [44, 45]. Inflammation, oxidative stress and cortical atrophy are three factors that play essential roles in the development of both dementia and frailty [46]. Previous studies reported that in a population of cognitively declining patients, frailty is associated with the presence, degree, and localization of cerebral atrophy. For every $1 \%$ increase in FI, the probability of cortical atrophy increased by $2 \%$ [43].

In a long-term follow-up cohort study, participants may become deceased during the follow-up period, especially those who are frail. In this study, the mortality of the participants was almost one-fifth, and these censored data can lead to bias. Therefore, competing risk models were applied to analyse death as a competing event to dementia, which decreased the bias of non-dementia premature death in the association of frailty and incident dementia. Table 3 shows that multidimensional frailty was more highly associated with incident dementia after controlling for age, gender, education level, physical multimorbidity, walking distance per week, smoking status, and alcohol use. The HRs of competing risk hazard models were lower than those of the Cox proportional hazards model. The results of this study suggest that the Cox proportional hazards model might overestimate the risk of incident dementia but that the competing risk hazard model is able to calculate unbiased and accurate outcomes.
According to the data in Table 4, frailty was not associated with incident dementia in the lowest quartile age group of the participants at baseline. In contrast, the other group had a significantly higher risk of incident dementia if they met the definition of multidimensional frailty at baseline. Thus, there was a positive association between age and multidimensional frailty. The gradual decline in physiological reserve with ageing accelerates faster in frail people than in non-frail people [47]. This observation is also in-line with other studies, showing that the risk of incident dementia increases with decreasing physiological reserve in elderly individuals [48].

There are two limitations in this study. First, grip strength information was not collected at the baseline, so the models of this study did not analyse grip strength as a variable of frailty. But previous studies of 10/66 group have suggested that the link between grip strength and adverse health conditions weakens when other frailty indicators and confounding factors are accounted for [49], although grip strength was one of the five indicators of Fried frailty phenotype. Therefore, this study was consistent with former 10/66 dementia study [30]. Second, this cohort study was not nationally representative, so the external validity of prevalence and cumulative incidence was not as good as the internal validity. However, this study did focus on exploring the association between frailty and dementia, rather than on the prevalence of dementia in the national population.

In the future, additional studies are needed to confirm the associations between subtypes of dementia and frailty to determine potential causes of dementia to prevent elderly people from developing the condition. Other important comorbidities, such as hyperlipidaemia, stroke, or cancers, require further analyses. Moreover, to explain the mechanism between frailty and dementia in dementia studies, biomarkers should be considered vital mediators for predicting the condition. Future cohort 
studies should take into consideration psycho-social and biological factors to build a more accurate prediction model.

\section{Conclusions}

Frailty, including physical and cognitive dimensions, plays an inherent role in incident dementia, being more significant in elderly people. Compared to physical frailty, multidimensional frailty assessment formed by physical, mental status and social relations, can better explain the dynamic association between frailty and incident dementia. The present findings are significant for distinguishing high-risk older persons and may provide an opportunity for intervention to reduce the impacts of dementia on personal and social well-being.

\section{Abbreviations \\ Cl: Confidence interval; CSI-D: Community Screening Instrument for Dementia; DSM: Diagnostic and Statistical Manual of Mental Disorders; GMS: Geriatric Mental State; HRs: Hazard ratios; MFI: Multidimensional Frailty Index; PFI: Physical Frailty Index; SD: Standard deviation; WHO: World Health Organization \\ Acknowledgements \\ We thank Dr. Cunli Xiao and her colleagues from Ping An Hospital in Xicheng district and Drs. Zhihua Zheng, Jinli Zhu and their colleagues from the Institute of Mental Health Care in Daxing District for their collaboration in the fieldwork conducted in Beijing. We thank Prof. Yueqin Huang's PhD students Fang Yan, Chuanjun Zhuo and Ying Wang for their hard work in the field survey. We also appreciate Dr. William A Jefferson from Chinese Academy of Science for help with English grammar and wording in the manuscripts.}

\section{Authors' contributions}

$\mathrm{ML}$ conceived the idea, run the data analysis and wrote the manuscript. YH and ZL contributed to the design and the implementation of the research and to the writing of the manuscript. HC and CM contributed to data collection and fieldwork. RS and TZ involved in planning and supervising the work. SL supervised all the work. MP contributed to the design of the survey All authors discussed the main findings and contributed to the discussion writing. The author(s) read and approved the final manuscript

\section{Funding}

The research was funded by the World Health Organisation (prevalence phase), Wellcome Trust Health Consequences of Population Change Programme [GR080002] (incidence phase), and the European Research Council [ERC-2013-ADG340755 LIFE2YEARS1066] (ongoing data collection, and further analyses of existing data).

\section{Availability of data and materials}

The data underlying this study are restricted, as participants did not consent to sharing their information publicly. Data underlying the results presented in the study are available from the 10/66 Dementia Research Group public data archive for researchers who meet the criteria for access to confidential data. Information on procedures to request access is available at https:// www.alz.co.uk/1066/1066_public_archive_baseline.php, or by contacting dementiaresearchgroup1066@kcl.ac.uk

\section{Ethics approval and consent to participate}

This study was approved by Institutional Review Board of Institute of Mental Health in Peking University, and by the King's College London research ethics committee. Written informed consent was obtained from all participants included.

\section{Consent for publication}

Not applicable.

\section{Competing interests}

The authors declare that they have no competing interests.

\section{Author details}

${ }^{1}$ Peking University Sixth Hospital, Peking University Institute of Mental Health, National Health Committee Key Laboratory of Mental Health (Peking University), National Clinical Research Center for Mental Disorders (Peking University Sixth Hospital), Beijing, China. ${ }^{2}$ Global Health Institute, King's College London, London, UK.

Received: 20 December 2019 Accepted: 29 March 2020

Published online: 15 April 2020

\section{References}

1. Who: Dementia. https://www.who.int/health-topics/dementia\#tab=tab_1 (2019). Accessed 7 Oct 2019.

2. Ferri CP, Prince M, Brayne C, Brodaty H, Fratiglioni L, Ganguli M, et al. Global prevalence of dementia: a Delphi consensus study. Lancet. 2005;366(9503): 2112-7.

3. Huang Y, Liu Z, Wang H, Guan X, Chen H, Ma C, et al. The China mental health survey (CMHS): I. background, aims and measures. Soc Psychiatry Psychiatr Epidemiol. 2016;51(11):1559-69.

4. Liu Z, Huang Y, Lv P, Zhang T, Wang H, Li Q, et al. The China mental health survey: II. Design and field procedures. Soc Psychiatry Psychiatr Epidemiol. 2016;51(11):1547-57.

5. Huang Y, Wang Y, Wang H, Liu Z, Yu X, Yan J, et al. Prevalence of mental disorders in China: a cross-sectional epidemiological study. Lancet Psychiatry. 2019:6(3):211-24.

6. Salas A, Sosa AL, Williams JD, Dewey ME. Dementia incidence and mortality in middle-income countries, and associations with indicators of cognitive reserve: a 10/66 dementia research group population-based cohort study the lancet. Lancet. 2012;380(9836):50-8.

7. Whitmer RA, Sidney S, Selby J, Johnston SC, Yaffe K. Midlife cardiovascular risk factors and risk of dementia in late life. Neurology. 2005;64(2):277-81.

8. Fine L, Philogene GS, Gramling R, Coups EJ, Sinha S. Prevalence of multiple chronic disease risk factors. 2001 National Health Interview Survey. Am J Prev Med. 2004;27(Suppl 2):18-24.

9. Pronk NP, Anderson LH, Crain AL, Martinson BC, O'Connor PJ, Sherwood NE, et al. Meeting recommendations for multiple healthy lifestyle factors. Prevalence, clustering, and predictors among adolescent, adult, and senior health plan members. Am J Prev Med. 2004;27(Suppl 2):25-33.

10. Poortinga $W$. The prevalence and clustering of four major lifestyle risk factors in an English adult population. Prev Med. 2007;44(2):124-8.

11. Wakabayashi I. Age-dependent influence of gender on the association between obesity and a cluster of cardiometabolic risk factors. Gender Med. 2012;9(4):267-77.

12. Griffin B, Sherman KA, Jones M, Bayl-Smith P. The clustering of health behaviours in older Australians and its association with physical and psychological status, and sociodemographic indicators. Ann Behav Med. 2014;48(2):205-14

13. Kojima G, Taniguchi Y, lliffe S, Walters K. Frailty as a predictor of Alzheimer disease, vascular dementia, and all dementia among community-dwelling older people: a systematic review and meta-analysis. J Am Med Dir Assoc. 2016;17(10):881-8.

14. Fried LP, Hadley EC, Walston JD, Newman AB, Guralnik JM, Studenski S, et al. From bedside to bench: research agenda for frailty. Sci Aging Knowl Environ. 2005;2005(31):pe24.

15. Momma H, Sawada SS, Kato K, Gando Y, Kawakami R, Miyachi M, et al. Physical fitness tests and type 2 diabetes among Japanese: a longitudinal study from the Niigata wellness study. J Epidemiology. 2019;29(4):139-46.

16. Lawman HG, Troiano RP, Perna FM, Wang CY, Fryar CD, Ogden CL. Associations of relative handgrip strength and cardiovascular disease biomarkers in US adults, 2011-2012. Am J Prev Med. 2016;50(6):677-83.

17. Buchman AS, Schneider JA, Leurgans S, DAJN B. Physical frailty in older persons is associated with Alzheimer disease. Pathology. 2008;71(7):499-504.

18. Xue M, Xu W, Ou YN, Cao XP, Tan MS, Tan L, et al. Diabetes mellitus and risks of cognitive impairment and dementia: a systematic review and metaanalysis of 144 prospective studies. Ageing Res Rev. 2019;55:100944.

19. Peters R, Booth A, Rockwood K, Peters J, D'Este C, Anstey KJ. Combining modifiable risk factors and risk of dementia: a systematic review and metaanalysis. BMJ Open. 2019;9(1):e022846. 
20. Bishop NA, Lu T, Yankner BA. Neural mechanisms of ageing and cognitive decline. Nature. 2010;464(7288):529-35.

21. Miller DB, O'Callaghan JP. Aging, stress and the hippocampus. Ageing Res Rev. 2005;4(2):123-40.

22. Panegyres PK. The contribution of the study of neurodegenerative disorders to the understanding of human memory. QJM. 2004;97(9):555-67.

23. Dupre ME, Gu D, Warner DF, Yi Z. Frailty and type of death among older adults in China: prospective cohort study. BMJ. 2009:338:b1175.

24. He B, Ma Y, Wang C, Jiang M, Geng C, Chang X, et al. Prevalence and risk factors for frailty among community-dwelling older people in China: a systematic review and meta-analysis. J Nutr Health Aging. 2019;23(5):44250 .

25. Soleman N, Chandramohan D, Shibuya K. Verbal autopsy: current practices and challenges. Bull World Health Organ. 2006;84(3):239-45.

26. Prina AM, Acosta D, Acostas I, Guerra M, Huang Y, Jotheeswaran AT, et al. Cohort Profile: The 10/66 study. Int J Epidemiol. 2016;1-10.

27. Copeland JRM, Prince M, Wilson KCM, Dewey ME, Payne J, Gurland B. The Geriatric mental state examination in the 21st century. Int J Geriatr Psychiatry. 2002;17(8):729-32

28. Prince M, Ferri CP, Acosta D, Albanese E, Arizaga R, Dewey M, et al. The protocols for the 10/66 dementia research group population-based research programme. BMC Public Health. 2007;7(1):165.

29. Prince M. Dementia in developing countries. A consensus statement from the 10/66 dementia research group. Int J Geriatr Psychiatry. 2000;15(1):1420.

30. Llibre Rodriguez JJ, Prina AM, Acosta D, Guerra M, Huang Y, Jacob KS, et al. The Prevalence and Correlates of Frailty in Urban and Rural Populations in Latin America, China, and India: A 10/66 Population-Based Survey. J Am Med Directors Assoc. 2018;19(4):287-95 e284.

31. Kim SW, Han HS, Jung HW, Kim Kl, Hwang DW, Kang SB, et al. Multidimensional frailty score for the prediction of postoperative mortality risk. JAMA Surg. 2014;149(7):633-40.

32. Song $X$, Mitnitski A, Rockwood K. Prevalence and 10-year outcomes of frailty in older adults in relation to deficit accumulation. J Am Geriatr Soc. 2010; 58(4):681-7.

33. Resources DUOA, Program S. Multidimensional functional assessment, the OARS methodology: a manual: Center for the Study of Aging and human development: Durham, NC Duke University; 1978.

34. Doraiswamy PM, Bieber F, Kaiser L, Krishnan KR, Reuning-Scherer J, Gulanski B. The Alzheimer's disease assessment scale: patterns and predictors of baseline cognitive performance in multicenter Alzheimer's disease trials. Neurology. 1997;48(6):1511-7.

35. Lin HR, Tsuji T, Kondo K, Imanaka Y. Development of a risk score for the prediction of incident dementia in older adults using a frailty index and health checkup data: the JAGES longitudinal study. Prev Med. 2018;112:8896.

36. Liu HX, Ding G, Yu WJ, Liu TF, Yan AY, Chen HY, et al. Association between frailty and incident risk of disability in community-dwelling elder people: evidence from a meta-analysis. Public Health. 2019;175:90-100.

37. Hugo J, Ganguli M. Dementia and cognitive impairment. Clin Geriatr Med. 2014;30(3):421-42.

38. Namioka N, Hanyu H, Hirose D, Hatanaka H, Sato T, Shimizu SJG, et al. Oxidative stress and inflammation are associated with physical frailty in patients with Alzheimer's disease. Geriatr Gerontol Int. 2016;17(6):913-8.

39. Shimada H, Doi T, Lee S, Makizako H, Chen L-K, Arai H. Cognitive frailty predicts incident dementia among community-dwelling older people. J Clin Med. 2018;7(9):250

40. Livingston G, Sommerlad A, Orgeta V, Costafreda SG, Huntley J, Ames D, et al. The lancet international commission on dementia prevention and care. Lancet. 2017;390:2673-734.

41. Rogers NT, Steptoe A, Cadar D. Frailty is an independent predictor of incident dementia: evidence from the English longitudinal study of ageing. Sci Rep. 2017;7(1):15746.

42. Panza F, Lozupone M, Solfrizzi V, Stallone R, Bellomo A, Greco A, et al. Cognitive frailty: a potential target for secondary prevention of dementia. Expert Opin Drug Metab Toxicol. 2017;13(10):1023-7.

43. Gallucci M, Piovesan C, Di Battista ME. Associations between the frailty index and brain atrophy: the Treviso dementia (TREDEM) registry. J Alzheimers Dis. 2018;62(4):1623-34.
44. Dumont C, Voisin T, Nourhashemi F, Andrieu S, Koning M, Vellas B. Predictive factors for rapid loss on the mini-mental state examination in Alzheimer's disease. J Nutr Health Aging. 2005;9(3):163-7.

45. Borges MK, Canevelli M, Cesari M, Aprahamian I. Frailty as a predictor of cognitive disorders: a systematic review and meta-analysis. Front Med. 2019; 6:1-8.

46. Mulero J, Zafrilla P, Martinez-Cacha A. Oxidative stress, frailty and cognitive decline. J Nutr Health Aging. 2011;15(9):756-60.

47. Ruan Q, D'Onofrio G, Sancarlo D, Greco A, Lozupone M, Seripa D, et al. Emerging biomarkers and screening for cognitive frailty. Aging Clin Exp Res. 2017;29(6):1075-86

48. Panza F, Lozupone M, Solfrizzi V, Sardone R, Dibello V, Di Lena L, et al. Different cognitive frailty models and health- and cognitive-related outcomes in older age: from epidemiology to prevention. J Alzheimers Dis. 2018:62(3):993-1012.

49. Prina AM, Stubbs B, Veronese N, Guerra M, Kralj C, Llibre RJJ, et al. Depression and incidence of frailty in older people from six Latin American countries. Am J Geriatr Psychiatry. 2019;27(10):1072-9.

\section{Publisher's Note}

Springer Nature remains neutral with regard to jurisdictional claims in published maps and institutional affiliations.
Ready to submit your research? Choose BMC and benefit from:

- fast, convenient online submission

- thorough peer review by experienced researchers in your field

- rapid publication on acceptance

- support for research data, including large and complex data types

- gold Open Access which fosters wider collaboration and increased citations

- maximum visibility for your research: over $100 \mathrm{M}$ website views per year

At BMC, research is always in progress.

Learn more biomedcentral.com/submissions 